\title{
Diagnostic Aspects and Haematobiochemical Changes Associated with Canine Parvoviral Enteritis in Dogs
}

\author{
M. Bhargavi ${ }^{1 *}$, B. Shobhamani ${ }^{2}$ K. Nalini Kumari ${ }^{2}$ and Ch. Srilatha ${ }^{3}$ \\ ${ }^{1}$ Department of Veterinary Medicine, NTR College of Veterinary Science, \\ Gannavaram, 521101, Andhra Pradesh, India \\ ${ }^{2}$ Department of Veterinary Medicine, ${ }^{3}$ Department of Veterinary Pathology, College of \\ Veterinary Science, SVVU, Tirupati - 517502, Andhra Pradesh, India \\ *Corresponding author
}

Keywords

Canine parvovirus,

Haematology, Serum

biochemistry.

Article Info

Accepted:

26 September 2017

Available Online:

10 November 2017

\section{A B S T R A C T}

Canine parvoviral enteritis is responsible for significant morbidity and mortality among the pups and sometimes adult dogs (if treatment is delayed). Hence, early diagnosis of the infection has utmost importance. In the present study, canine parvovirus infection (CPV) infection was detected in fourteen pups by positive test with sandwich lateral flow immunochromatography assay (Scanvet ${ }^{\mathrm{TM}}$ PARVO). The prominent haematological changes noticed were anemia, lymphopenia, thrombocytopenia and neutrophilia. Significantly elevated blood urea nitrogen (BUN) and a significant decrease in the levels of serum potassium were the important biochemical alterations noticed in CPV positive pups.

\section{Introduction}

Since its emergence in 1978, canine parvoviral enteritis was and remains a common and important cause of morbidity and mortality in young dogs. The continued incidence of parvoviral enteritis is partly due to the virus's capability to "reinvent" itself and evolve into new more virulent and resistant subspecies (Goddard and Leisweitz, 2010). Today CPV-2a and CPV-2b are still the most common parvovirus species causing disease in canines globally. Within the past decade a new strain called as CPV-2c was emerged (Goddard and Leisewitz, 2010) and occurrence of CPV-2c was first reported in
India in 2010 (Nandi et al., 2010) based on the sequence analysis of $\mathrm{CPV}-2 \mathrm{~b}$ positive samples (Nandi and Kumar, 2010). Enteritis and myocarditis are the two disease entities associated with CPV-2 infection. This disease occurs at any age group but severe acute enteritis is most common in puppies between 6 weeks and 6 months. The disease may be tentatively diagnosed based on clinical signs and confirmation was achieved by various diagnostic tests. However, a rapid diagnosis of CPV infection is much important in dog's population to confirm the disease, to isolate the infected dogs and to prevent secondary 
infections of susceptible contact animals (Decaro and Buonavoglia, 2012, Al- Tayib 2014)). The leukocyte count during CPV enteritis is generally characterized as significantly depressed, with a transient lymphopenia being the most consistent finding (Goddard and Leisweitz, 2010). Pups dying from the disease generally have total leukocytes equal to or less than 1030 cells $/ \mu \mathrm{L}$ and have persistent lymphocytopenia, monocytopenia and eosinopenia within first 3 days of hospitalization (Greena and Decaro., 2012). The present study was undertaken to diagnose parvoviral infection in pups with rapid sandwich lateral flow immunochromatographic assay and to study certain hematobiochemical changes associated with parvoviral enteritis in dogs.

\section{Materials and Methods}

\section{Detection of parvoviral antigen in the faecal samples}

Parvoviral antigen in the faeces was detected by sandwich lateral flow immune chromatography assay as per the protocol provided along with Scan Vet ${ }^{\mathrm{TM}}$ PARVO kit as detailed below. In the present study, faecal samples from twenty four CPV suspected pups with symptoms of vomiting, bloody foul smelling diarrhoea, fever, dehydration etc., were tested for CPV antigen with Scan $\mathrm{Vet}^{\mathrm{TM}}$ PARVO kit. The faecal sample was collected by inserting the sterile swab which was provided along with kit into the rectum. For good sample extraction, swab was immersed into the diluent provided and rotated. The sample was left for a short time and finally 3 drops of supernatent was added to the sample hole of the cassette provided in the kit. As the test began to work, a purple color was observed across the result window in the centre of the test device. Interpretation of the test results was done after 5- 10 minutes as per the manufacturer's instructions in brochure as below. The sample was considered positive for the presence of $\mathrm{CPV}$ if two purple bands one in the control line (C) and other in the test line (T) appeared. The sample was considered as negative for $\mathrm{CPV}$ if one purple band appears in the control line (C) with no apparent band in the test line (T). If no purple band appears in the control line (C) or if a band appears in the test line (T) but not in the control line (C), the test was considered as invalid.

\section{Estimation of haematobiochemical parameters}

Approximately $5 \mathrm{ml}$ of blood was collected from cephalic vein or saphenous vein as per standard protocols, for hemato-biochemical studies. Two $\mathrm{ml}$ of blood was transferred into a dry vial containing 10 per cent EDTA for complete blood picture and remaining $3 \mathrm{ml}$ was transferred to clot activator vial for serum. Haematological parameters like haemoglobin (gm\%, Sahli's hemoglobinometer), packed cell volume (\%, microhematocrit method), total erythrocyte count (millions per cumm, haemocytometer), total leucocyte count (per cumm, haemocytometer), differential leucocyte count (\%, battlement method) and platelet count (lakhs per cumm) were studied in apparently healthy dogs and CPV positive patients on the day of presentation.

Serum biochemical parameters like blood urea nitrogen $(\mathrm{mg} / \mathrm{dl})$, total protein $(\mathrm{gm} / \mathrm{dl})$ serum potassium (mmol/l), serum sodium $(\mathrm{mmol} / \mathrm{l})$, serum chloride $(\mathrm{mmol} / \mathrm{l})$ were estimated by using Autospan liquid gold diagnostic kits and blood glucose (mg/dl) using glucometer. The results obtained were tabulated and subjected to statistical analysis as per the procedures described by Snedecor and Cochran (1994) and by using SPSS (15.0) software and Graph pad Prism software (6.0"version). 


\section{Results and Discussion}

In the present study, patients (24) presented with symptoms suggestive of parvoviral enteritis were tested with the Scanvet parvoviral antigen detection kit, of which 14 were found to be positive (Figure 1) for the CPV infection and opined that it was a rapid, sensitive and simple diagnostic tool. Previously, Pillai and Deepa (2010), Filipov et al., (2011) and Dongre et al., (2013) employed immunochromatography based test kits for the detection of parvovirus in faecal samples of dogs. Mohyedini et al., (2013) compared PCR and immunochromatography (IC) diagnostic techniques to detect $\mathrm{CPV}$ and concluded that IC based office test kits are sensitive and reliable in comparison with molecular methods. SensPERT, an immunochromatography based assay kit was considered as rapid, simple, very quick and useful diagnostic tool for determining CPV status in dog population (Al- Tayib., 2014).

The mean values of haemato-biochemical parameters of 6 apparently healthy dogs and 14 dogs with canine parvoviral enteritis is presented in Table 1 . In the present study, the mean value of haemoglobin was decreased significantly ( $\mathrm{p}<0.05$ level) $(9.77+0.84 \mathrm{gm} \%)$ when compared to healthy dogs $(12.92+0.25$ gm\%), while it was insignificant at $\mathrm{p}<0.01$ level. And critical examination revealed high levels (15- $17 \mathrm{gm} / \mathrm{dl})$ in three patients (21.43\%), normal haemoglobin in three patients $(21.43 \%)$ and anaemia (2.7- 8.1 $\mathrm{gm} / \mathrm{dl})$ in eight pups $(57.14 \%)$ which might be due to the loss of blood due to gastric and intestinal haemorrhages, was in accordance with Biswas et al., (2005). Anaemia is a common finding in CPV enteritis, especially in the later phase of severe disease and the cause of this is unlikely to be suppression of erythropoiesis, as circulating red blood cells have a long half-life relative to the short period during which the virus suppresses production in the bone marrow (Goddard and Leisweitz., 2010). In the present study, high levels of haemoglobin in 3 pups might be due to dehydration (Weiss and Tvedten, 2004). The mean value of packed cell volume (PCV) in affected dogs $(28.77+2.73 \%)$ was significantly $(\mathrm{p}<0.05$ level $)$ decreased when compared to healthy dogs $(38.25+0.37 \%)$, while it was insignificant at $\mathrm{p}<0.01$ level. On detailed analysis, eight patients $(57.14 \%)$ had decreased PCV (6.3-24.6\%) which might be due to intestinal bleeding, was in accordance with the findings of Bhat et al., (2013). However increased PCV (48-53\%) in three patients $(21.43 \%)$ might be due to dehydration resulted from severe fluid loss through vomitus and faeces, as reported by Biswas et al., (2005). Normal PCV in the remaining three pups might be due to dehydration in anaemic condition. In the similar manner, there was a significant decrease in the mean total erythrocyte count of affected dogs $(3.86+0.29$ millions/cumm) when compared to healthy dogs $(6.28+0.89$ millions/cumm). However, detailed analysis revealed elevated R.B.C in three pups $(21.43 \%)$, decreased R.B.C in eight pups $(57.14 \%)$ and normal count in three pups $(21.43 \%)$. Healthy dogs had a mean total leucocyte count of $8533.33+379.18$ per cumm. The mean value of total leukocyte count (TLC) in the parvoviral enteritis dogs $(10600+1822.87$ /cumm) was insignificantly increased when compared to healthy dogs. However critical examination revealed leucopenia (1800- 5200 /cumm) in six patients (42.86\%), leucocytosis $(19,000-$ 25,000 /cumm) in four puppies $(28.57 \%)$ and normal count in four puppies $(42.86 \%)$. In the present study, destruction of leucocyte progenitor cells might be the cause of leucopenia in some patients, as also suggested by Macartney et al., (1984) and Goddard and Leisweitz (2010) who stated that depressed leucocyte count in CPV enteritis is attributable to the destruction of 
haematopoetic progenitor cells of the various leucocyte types in the bonemarrow and other lymphoproliferative organs such as the thymus, lymphnodes and spleen which results in inadequate supply for the massive demand for leucocytes in the inflamed gastrointestinal tract. Leucopenia was reported frequently in parvoviral enteritis in dogs earlier by Rai et al., (1994), Yilmaz and Senturk (2007) and Castro et al., (2013). Leucocytosis in the present study might be due to the invasion of bacteria on damaged intestinal tract as opined by Mohan et al., (1991), Rai et al., (1994) and McCandlish (1998), who stated that increased TLC in CPV enteritis might be due to the progression of disease in which a reactive leucocytosis had occurred due to myeloid hyperplasia or collection of the samples at the later stages rather than in the initial stage of viraemia and also due to secondary bacterial infections.

In the present study, concomitant virusinduced lymphopenia, and neutrophilia consequent to infections by oppurtunistic bacteria might have contributed to the normal leucocyte count, as also suggested by Decaro and Buonavoglia (2012). Rai et al., (1994) reported normal leucocyte count in $6 \mathrm{CPV}$ cases and stated that those animals with normal TLC range might have been in transition stage of leucopenia to leucocytosis. In the present study, mean neutrophil count in the group containing healthy dogs was 66.67 +0.803 percent, while in CPV affected dogs it was increased significantly ( $\mathrm{p}<0.01$ level) to $77.45+1.29$ percent. However upon detailed analysis, neutropenia (30-40\%) was recorded in 28.57 percent of patients (4 pups) while relative neutrophilia was seen in 42.86 percent of patients (6 pups). In the present study, neutropenia in 4 pups might be due to the destruction of mitotically active precursors of circulating leucocytes by CPV which was in accordance with the findings of
Greene and Decaro (2012). Both Peripheral neutrophil consumption (especially in the gastrointestinal tract) and destruction of progenitor cells within the bonemarrow might contribute to neutropenia (Rewerts and Cohn., 2000).

Previously neutropenia in some Beagle dogs (Harcourt et al., 1980) and absolute neutropenia in 25 dogs affected with parvoviral enteritis (Mohan et al., 1991) were reported. Neutrophilia recorded in this study simulated with the findings associated with secondary bacterial complications in parvoviral enteritis. The mean value of lymphocytes was significantly decreased $(13.27+1.17 \%)$ when compared to healthy dogs $(22.67+0.67 \%)$ and six pups had lymphopenia (42.86\%), while the remaining eight pups $(57.14 \%)$ had normal values on critical examination. The mean values of monocytes $(3.36+0.43 \%)$ and eosinophils $(3.0+0.24 \%)$ were insignificantly decreased when compared to healthy dogs. In the present study, the mean value of thrombocyte count of affected dogs was significantly $(p<0.01 \quad$ level $) \quad$ decreased $(264714.30+37911.18$ /cumm $)$ when compared with the apparently healthy dogs $(456166.66+22918.22$ /cumm).

Critical examination revealed severe thrombocytopenia $(63,000-1,62.000 / \mathrm{cumm})$ in five puppies $(35.71 \%)$ which might be because of decreased platelet production or as a result of direct action of viruses and/or immunologic components on platelets or endothelium as suggested by Shah et al., (2013). It may also result from increased platelet utilisation in the gastrointestinal tract combined with destruction of megakaryocyte bonemarrow precursors (Rewerts and Cohn, 2000). Earlier, similar observations were made by Yilmaz and Senturk (2007). 
Table.1 Mean haematobiochemical values of apparently healthy dogs and CPV affected pups (Mean \pm S.E)

\begin{tabular}{|c|c|c|c|}
\hline Parameter & $\begin{array}{l}\text { Apparently healthy dogs } \\
(\mathbf{n = 6 )}\end{array}$ & CPV affected pups (n=14) & t-calculated value \\
\hline $\mathrm{Hb}(\mathrm{gm} \%)$ & $12.92 \pm 0.25^{\mathrm{a}}$ & $9.97 \pm 0.84^{b}$ & $2.25^{*}$ \\
\hline PCV $(\%)$ & $38.25+0.37^{\mathrm{a}}$ & $28.2 \overline{7}+2.73^{\mathrm{b}}$ & $2.35^{*}$ \\
\hline TEC (m/cumm) & $6.28 \pm 0.89^{\mathrm{a}}$ & $3.86+0.29^{b}$ & $3.67^{* * 4}$ \\
\hline TLC/cumm & $8533.33 \pm 379.18^{\mathrm{a}}$ & $10600 \pm 1822.87^{\mathrm{a}}$ & $1.59^{\mathrm{NS}}$ \\
\hline \multicolumn{4}{|l|}{ DLC } \\
\hline $\mathrm{N}(\%)$ & $70.0 \pm 0.73^{\mathrm{a}}$ & $77.45 \pm 1.29^{\mathrm{b}}$ & $3.63^{* *}$ \\
\hline $\mathrm{L}(\%)$ & $22.67 \pm 0.67^{\mathrm{a}}$ & $13.27 \pm 1.17^{\mathrm{b}}$ & $5.04^{* *}$ \\
\hline $\mathrm{M}(\%)$ & $4.17 \pm 0.31^{\mathrm{a}}$ & $3.36 \pm 0.43^{\mathrm{a}}$ & $1.16^{\mathrm{NS}}$ \\
\hline $\mathrm{E}(\%)$ & $3.8+0.49^{\mathrm{a}}$ & $3.0+0.24^{\mathrm{a}}$ & $1.65^{\mathrm{NS}}$ \\
\hline Platelets (/cumm) & $456166.66+22918.22^{a}$ & $264714.3+37911.18^{b}$ & $3.16^{\text {** }}$ \\
\hline Blood urea nitrogen $(\mathrm{mg} / \mathrm{dl})$ & $10.47 \pm 1.13^{\mathrm{a}}$ & $36.48+6.16^{\mathrm{b}}$ & $2.71^{*}$ \\
\hline Total serum protein $(\mathrm{gm} / \mathrm{dl})$ & $7.17 \pm 0.09^{\mathrm{a}}$ & $6.53 \pm 0.31^{\mathrm{a}}$ & $1.32^{\mathrm{NS}}$ \\
\hline Blood glucose (mg/dl) & $100.67 \pm 6.69^{\mathrm{a}}$ & $111.07 \pm 9.49^{\mathrm{a}}$ & $0.68^{\mathrm{NS}}$ \\
\hline Serum potassium $(\mathrm{mmol} / \mathrm{l})$ & $4.82 \pm 0.11^{\mathrm{a}}$ & $3.59 \pm 0.14^{b}$ & $5.39^{* * 4}$ \\
\hline Serum sodium $(\mathrm{mmol} / \mathrm{l})$ & $144.03 \pm 0.81^{\mathrm{a}}$ & $144.78 \pm 2.40^{\mathrm{a}}$ & $0.19^{\mathrm{NS}}$ \\
\hline Serum chloride $(\mathrm{mmol} / \mathrm{l})$ & $111.33+1.06^{\mathrm{a}}$ & $107.07+1.66^{\mathrm{a}}$ & $1.60^{\mathrm{NS}}$ \\
\hline
\end{tabular}

Means followed by same superscript don't differ significantly

*Significant at $\mathrm{p}<0.05$ level

${ }^{* * *}$ Significant at $\mathrm{p}<0.01$ level

NS: Non significant

Fig.1 a. Positive and b. Negative test with Scanvet ${ }^{\mathrm{TM}}$ PARVO kit (M/S INTAS Pharmaceuticals Ltd., Ahmedabad, India)

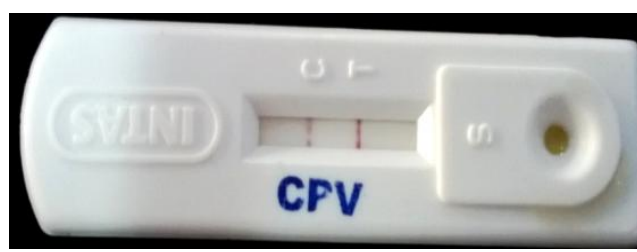

a. Positive test

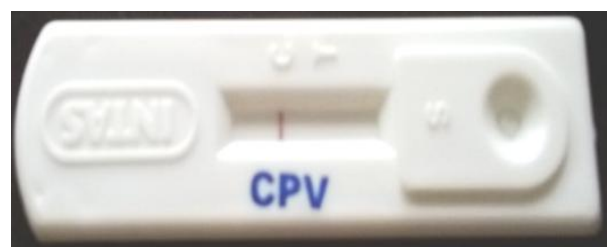

b.Negative test

\section{Control; T Test}

The mean value of blood urea nitrogen in healthy dogs was $10.47+1.13$ milli gram per decilitre while it was significantly $(\mathrm{p}<0.05$ level) increased in affected dogs $(36.48+6.16$ $\mathrm{mg} / \mathrm{dl}$ ) which might be due to prerenal azotemia which might have resulted from reduced glomerular filteration rate, as suggested by Biswas et al., (2005). Critical examination revealed elevated BUN (40.2-
$89.83 \mathrm{mg} / \mathrm{dl})$ in seven patients $(50 \%)$ and normal levels in seven patients (50\%). Elevated BUN in parvoviral affected dogs was frequently reported (Nappert et al., 2002, Yilmaz and Senturk., 2007 and Shah et al., 2013). Further blood urea nitrogen concentration was higher in non-survival parvoviral affected puppies as compared with survival and healthy dogs at the day of 
admission (Bastan et al., 2013). In affected dogs, the mean value of total protein $(6.53+$ $0.31 \mathrm{gm} / \mathrm{dL}$ ) was insignificantly decreased when compared to healthy dogs $(7.17+0.09$ $\mathrm{gm} / \mathrm{dL}$ ) which might be due to anorexia, malabsorption and ongoing protein loss. Detailed analysis revealed decreased total protein $(3.12-4.17 \mathrm{mg} / \mathrm{dl})$ in three puppies $(21.43 \%)$. Hypoprotenemia might be due to the leakage of serum protein through damaged capillaries of the villi of intestines and also due to less absorption through villi (Biswas et al., 2005). Earlier Baruah et al., (2007) and Sagar et al., (2008) reported decreased levels of total serum protein in dogs with parvoviral enteritis. Dongre et al., (2013) reported a significant decrease in total serum protein levels on zero day in $12 \mathrm{CPV}$ affected dogs. In the present study, an insignificant increase was observed in the mean blood glucose levels of affected dogs $(111.07+9.49$ $\mathrm{mg} / \mathrm{dl}$ ) when compared to healthy dogs $(100.67+0.69 \mathrm{mg} / \mathrm{dl})$. However, critical examination revealed hypoglycaemia (40-48 $\mathrm{mg} / \mathrm{dl})$ in three pups $(21.43 \%)$ which might be due to loss of appetite, and also resulted from inflammatory changes in intestine interfering with absorption of nutrients and lack of nutritional intake (Rewerts and Cohn., 2000). Also hypoglycemia might be due to decreased hepatic glucose production because of decreased blood supply to liver with portosystemic shunt which results in liver atrophy and liver cannot play its normal role in maintaining the blood glucose concentration (Joshi et al., 2012). Many authors (Sharma et al., 2012, Roy et al., 2010 and Joshi et al., 2012) also reported hypoglycaemia in puppies with parvovirus infection. In the present study, hyperglycemia $(143-165 \mathrm{mg} / \mathrm{dl})$ reported in six pups $(42.86 \%)$ might be associated with sepsis (Hoskins, 2006). In the present study, the mean value of serum potassium was significantly $\quad(\mathrm{p}<0.01$ level $)$ decreased $(3.59+0.14 \mathrm{mmol} / \mathrm{L})$ when compared to healthy dogs $(4.82+0.11 \mathrm{mmol} / \mathrm{dL})$. However, detailed analysis revealed hypokalemia $(2.58-3.13 \mathrm{mmol} / \mathrm{l})$ in five pups (35.71\%) which might be due to the loss of potassium in severe vomitions and diarrhoea as suggested by Nappert et al., (2002). Similarly hypokalaemia in puppies with canine parvovirus infection was documented by Panda et al., (2009) and Joshi et al., (2012). Decreased levels of serum sodium and potassium might be due to loss of chloride and sodium ions in vomition and loss of sodium and potassium through diarrhoea to some extent (Mohan et al., 1991). The mean serum sodium $(144.78+2.40 \mathrm{mmol} / \mathrm{l})$ and mean serum chloride $(107.07+1.66 \mathrm{mmol} / \mathrm{l})$ levels were not decreased significantly as compared with healthy group. However, careful examination revealed hyponatremia $(120 \mathrm{mmol} / \mathrm{l})$ in one pup and hypochloremia (97-105 mmol/l) in six pups (42.86\%). Severe vomiting, diarrhoea and dehydration in one pup might be responsible for hyponatremia, as suggested by Rewerts and Cohn (2000). Baruah et al., (2007), Haligur et al., (2009) and Joshi et al., (2012) reported hyponatremia in CPV enteritis in dogs. Hypochloremia in six pups might be due to the loss of chloride ions through vomitions and diarrhoea and resulting intestinal villous atrophy, which is in agreement with Burchell et al., (2014) who stated that vomitus and diarrhoea are electrolyte rich fluids and reported a hypochloraemic alkalosis in more severly affected puppies.

Based on the findings of present study, it was concluded that the CPV infection in 14 pups was diagnosed with sandwich lateral flow immunochromatography assay and the important haematobiochemical alterations noticed in CPV affected dogs were anaemia $(57.14 \%)$, leucopenia (42.86\%), neutropenia (28.57 \%), lymphopenia (42.86 \%), thrombocytopenia (35.71\%), elevated BUN (50 \%), hypoproteinemia (21.43 \%), 
hypoglycemia (21.43\%), hypokalemia (35.71 $\%)$ and hypochloremia (42.86 \%).

\section{References}

Al-Tayib, O. 2014.Simple test kit for rapid detection of the presence of canine parvovirus antigen from dog's faeces. Scientific Journal of Veterinary Advances. 3(4): 57-64.

Baruah, M. S., Hazarika, G. C., and Phukan, A. 2007. Clinicobiochemical profile in canine parvovirus infection. Indian Veterinary Journal. 84(2): 104-106.

Bastan, I., Kurtede, A., and Ozen, D. 2013. Prognostic usefulness of some parameters in dogs with canine parvovirus. Ankara Univ Vet Fak Derg. 60: 53-58.

Bhat, A. A., Wadhwa, D. R., and Khan, M. A. 2013. Therapeutic management of canine parvo viral (CPV) gastroenteritis. Veterinary Practitioner. 14(1): 96-97.

Biswas, S., Chakravorty, D., and Pradhan, N. R. 2005. Clinical and haemato-biochemical changes in parvovirus infection in dogs. Indian Journal of Veterinary Medicine. 25(1): 16-18.

Burchell, R. K., Schoeman, J. P., and Leisewitz, A. L. 2014. The central role of chloride in the metabolic acid-base changes in canine parvoviral enteritis. The Veterinary Journal 200(1):152-6.

Castro, T. X., Rita de Cassia, N., Garcia, C., Gonclaves, L. P. S., Costa, E. M., Marcello, G. C. G., Labarthe, N. V., and Mendes-deAlmeida, F. 2013. Clinical, hematological and biochemical findings in puppies with coronavirus and parvovirus enteritis. Canadian Veterinary Journal. 54: 885-888.

Decaro, N., and Buonavoglia, C. 2012. Canine parvovirus - A review of epidemiological and diagnostic aspects, with emphasis on type 2c.Veterinary Microbiology. 155: 112.

Dongre, J., Mehta, H. K., and Maheswari, P. 2013. Rapid diagnosis and clinical management of canine parvovirus infection. Intas polivet. 14 (1): 155-156.

Filipov, C., Decaro, N., Desario, C., Amorisco, F., Sciarretta, R., and Buonavoglia, C. 2011.
Canine parvovirus epidemiology in Bulgaria. Journal of Veterinary Diagnostic Investigation. 23:152-154.

Goddard, A., and Leisewitz, A. L. 2010. Canine Parvovirus. Vet Clin Small Anim. 40: 1041-1053.

Greene, C. E., and Decaro, N. 2012. Canine viral enteritis. In: Greene $\mathrm{C}$ E, Infectious diseases of the dog and cat, Fourth edition, W.B. Saunders, Elsevier., pp. 67- 74.

Haligur, M., Ozmen, O., Kenan, S., and Sahinduran, S. 2009. Clinical, pathological and immunohistochemical findings in diarrhoeic dogs and evaluation of canine parvoviral and coronaviral enteritis. Journal of Animal and Veterinary Advances. 8(4): 720-725.

Harcourt, R. A., Spurling, N. W., and Pick, C. R. 1980. Parvovirus infection in a Beagle colony. Journal of Small Animal Practice. 21(5): 293-302.

Hoskins, J. D. 2006. Canine viral enteritis. In: Greene C E, Infectious diseases of the Dog and Cat, $3^{\text {rd }}$ edition, W.B. Saunders Co., Phildelphia. pp 40-45.

Joshi, G., Singathia, R., Gattani, A., Yadav, R., and Lakhotia, R. L. 2012. Microbiochemical studies of canine parvovirus infection in puppies. Veterinary Practitioner. 13(2): 347- 348.

Macartney, L., McCandlish, I. A. P., and Thomson, H. 1984. Canine parvovirus enteritis- clinical, haematological and pathological features of experimental infection. Veterinary Record. 115(9): 201210.

McCandlish, I. 1998. Canine parvovirus infection. In:Gorman E, Canine Medicine and Therapeutics, fourth edition, Blackwell science limited, pp. 127-130.

Mohan, R., Nauriyal, D. C., and Singh, K. B. 1991. Haematological and biochemical alterations in canine parvo virus infection. Indian Journal of Veterinary Medicine. 11(1 \& 2): 52-53.

Mohyedini, Sh., Jamshidi, Sh., Rafati, S., Nikbakht, Gh. R, Malmasi, A., Taslimi, Y., and Akbareni, H. 2013. Comparison of immunochromatographic rapid test with molecular method in diagnosis of canine parvovirus. Iranian journal of veterinary 
medicine. 7(1): 57-61.

Nandi, S., Anbazhagan, R., and Kumar, M. 2010. Strain differentiation and characterisation of canine parvovirus by PCR and RE mapping. Indian Journal of Biotechnology. 9: $38-42$.

Nandi, S., and Kumar, M. 2010. Canine parvovirus: current perspective. Indian Journal of Virology. 21(1): 31-44.

Nappert, G., Dunphy, E., Ruben, D., and Mann, F. A. 2002. Determination of serum organic acids in puppies with naturally acquired parvoviral enteritis. Canadian Journal of Veterinary Research. 66(1): 15-18.

Panda, D., Patra, R. C., Nandi, S., and Swarup, D. 2009. Oxidative stress indices in gastroenteritis in dogs with canine parvoviral infection. Research in Veterinary Science. 86(1): 36-42.

Pillai, U. N., and Deepa, P. M. 2010. Rapid diagnosis and treatment of canine parvoviral enteritis. Intas Polivet. 11(II): 348-349.

Rai, A., Nauriyal, D. C., and Mohan, R. 1994. A note on haematological observations in canine parvo viral gastroenteritis. Indian Veterinary Journal.71 (11): 1150-1151.

Rewerts, J. M., and Cohn, L. A. 2000. CVT update: Diagnosis and treatment of canine parvovirus. In: Kirk R W Current Veterinary Therapy XIII, Small Animal Practice, W.B. Saunders, Philadelphia, London, pp 629- 632.

Roy, S., Roy, M., and Sagar, K. A. 2010. Haemato-biochemical and therapeutic studies of canine parvoviral infection. Intas Polivet. 11(2): 344-347.

Sagar, A., Roy, S., and Roy, M. 2008. Clinico, haemato-biochemical changes and diagnosis of canine parvoviral enteritis. Intas Polivet. 9 (2): 262-265.

Shah, S. A., Sood, N. K., Wani, N., Gupta, K., and Singh, A. 2013. Haemato-biochemical changes in canine parvoviral infection. Indian Journal of Veterinary Pathology. 37(2): 131-133.

Sharma, Joshi, S. K., Monika, S. K., Vyas, and Singh, Shakti, 2012. Clinical, haematobiochemical characterization and therapeutic management of canine parvoviral enteritis. Proceedings from International Congress of Canine practice on modern concepts in canine health and diseases of Human concern. IX ${ }^{\text {th }}$ Annual convention of Indian society for advancement of canine practice.

Snedecor, G.W., and Cochran, W.G. 1994. Statistical methods. Eighth edition, IOWA State University Press, Ames, IOWA, USA.

Weiss, D., and Tvedten, H. 2004. Erythrocyte disorders. In: Willard M D and Tvedten H, Small animal clinical diagnosis by laboratory methods, fourth edition, W.B. Saunders, Philadelphia, pp. 38-62.

Yilmaz, Z., and Senturk, S. 2007. Characterisation of lipid profiles in dogs with parvoviral enteritis. Journal of Small Practice. 48(11): 643-50.

\section{How to cite this article:}

Bhargavi, M., B. Shobhamani, K. Nalini Kumari and Srilatha, Ch. 2017. Diagnostic Aspects and Haematobiochemical Changes Associated with Canine Parvoviral Enteritis in Dogs. Int.J.Curr.Microbiol.App.Sci. 6(11): 3357-3364. doi: https://doi.org/10.20546/ijcmas.2017.611.394 